\title{
Monitoring and Improving Naltrexone Adherence in Patients with Substance Use Disorder
}

\author{
Virginia Perez-Macia ${ }^{1,2}$ \\ Mireia Martinez- Cortes ${ }^{3}$ \\ Jesus Mesones ${ }^{1,2}$ \\ Manuel Segura-Trepichio ${ }^{4}$ \\ Lorena Garcia-Fernandez (D) $^{3,5}$ \\ 'Vinalopó University Hospital, Elche, \\ Spain; ${ }^{2}$ Psychology and Psychiatry \\ Department, Catholic University of \\ Murcia, Murcia, Spain; ${ }^{3}$ University \\ Hospital of San Juan, Alicante, Spain; \\ ${ }^{4}$ IMED Elche Hospital, Elche, Spain; \\ ${ }^{5}$ Clinical Medicine Department, Miguel \\ Hernández University, Alicante, Spain
}

Correspondence: Virginia Perez-Macia 36 Vicente Fuentes Sansano Road, Elche (Alicante), 03205, Spain

Tel +34675550722

Email vperezmacia@gmail.com

\begin{abstract}
Objective: Naltrexone is an opioid antagonist used for the treatment of patients with opioid use disorder and alcohol use disorder. This population often presents problems of follow-up and therapeutic efficacy related to adherence to treatment. The purpose of our study is to provide an exhaustive summary of the current evidence regarding naltrexone adherence in people with substance use disorders and to identify possible variables that may influence adherence to naltrexone.
\end{abstract}

Methods: Two searches were performed in bibliographic databases (PubMed, Embase), and studies included in the systematic review were those published from January 1, 2011 to September 2020, with participants over 18 years of age, evaluating treatment with naltrexone in alcohol use disorder and opioid use disorder. From the total of 133 articles initially selected, 36 were included and analyzed in the systematic review.

Results: Naltrexone has not demonstrated superiority over other available treatments in terms of adherence and abstinence, although reinforcement systems have obtained favorable results as an additional strategy to improve adherence.

Conclusion: It is necessary to study other psychosocial variables involved in improving adherence, in addition to taking patient preferences into account in order to improve the external validity of the results.

Keywords: naltrexone, adherence, alcohol, opioid

\section{Introduction}

Both opioids and alcohol consumption have become a main public health problem worldwide that is also associated with severe comorbidity with other mental disorders and medical conditions, and adverse economic and social consequences. ${ }^{1-6}$ According to data from the National Institute on Drug Abuse (NIDA), in 2016 2.1 million people in the United States of America suffered from a disorder related to the consumption of opioids prescribed from the health system, 626,000 people were diagnosed with a harmful heroin use disorder, and 15,000 Americans died from heroin overdose the same year. ${ }^{7,8}$ Moreover, the estimated prevalence of alcohol use disorders is around 5\% in America and part of Europe and exceeds $10 \%$ in some eastern European regions. This has led the World Health Organization (WHO) to report that the percentage of current drinkers in the world is about $43.0 \%{ }^{1,9}$

There are several drug treatments for substance use disorders, including naltrexone, which is considered a competitive opioid antagonist indicated for the treatment of alcohol and opioid dependence, which has been used since the 1970s. In 1984, the Food and Drug Administration (FDA) approved its use for 
opioid dependence, and in 1993 for alcoholism, becoming the first drug showing a specific effect on craving. ${ }^{10,11}$ Naltrexone has proved to be effective in people with alcohol use disorders (AUD) compared to placebo, and it has also been postulated as a valid treatment alternative to the opioid agonists available to date. Nevertheless, its superiority compared to placebo has not been proven in retention and relapse rates in opioid use disorder (OUD). ${ }^{12-15}$ In patients with an OUD, a maintenance dose of $50 \mathrm{mg}$ of oral-naltrexone (O-NTX) per day, or of $380 \mathrm{mg}$ of delivered intramuscularly every 4 weeks and a period free of opiates between 7 and 10 days is needed after a detoxification intervention. $^{12}$

For a treatment to be effective in people with substance use disorders both in the cessation and rehabilitation phases, adherence is a necessary requirement. Adherence refers to the process by which patients take medications as prescribed. It is composed of three phases: 1) initiation, that refers to the taking of the first dose; 2) implementation, or degree to which a patient's actual dosage corresponds to the prescribed dosing regimen, from the first to the last dose; 3) discontinuation, indicating the end of intervention. ${ }^{17}$ Adherence to daily dosing has been recognized as a factor limiting long-term effectiveness. ${ }^{18}$

Extended-release naltrexone was first used in 1997 and has become an alternative to oral naltrexone, specifically because of its potential to improve adherence to treatment. ${ }^{19}$ By 2003, Foster, Brewer and Steele pointed that naltrexone implants were reported to be effective in completely preventing relapse during the first month after opioid detoxification. ${ }^{20}$ In addition, research has also shown better abstinence rates and reduced relapse in patients treated with naltrexone implants compared to traditional treatments for opioid dependence disorder. ${ }^{21}$ Both implants and depot injections of naltrexone have undergone remarkable development since their appearance. Since 2007, a depot injection of naltrexone has had a license for alcoholism treatment and can be used "off label" for opiate dependence. It has a duration of effect of 4-5 weeks, which is short compared to long-lasting implants, which are able to provide plasma levels of naltrexone effective in preventing relapses from $6-8$ weeks to 6 months. ${ }^{22}$

Different studies focused on adherence to naltrexone in people using alcohol, opioids or both substances have shown inconsistent results. ${ }^{23}$ Moreover, research points out the existence of other factors involved in naltrexone adherence in addition to the form of presentation, such as incentive systems and psychotherapy. ${ }^{24-27}$

Therefore, the aims of the present study are: 1) to provide an exhaustive summary of the current evidence regarding naltrexone adherence in people with substance use disorders in its different forms of presentation (oral or extended-release); and 2) to identify possible variables that may influence adherence to naltrexone in people with a substance use disorder.

\section{Materials and Methods}

A systematic review was enabled following the recommendations of the PRISMA guidelines (Preferred Reporting Items for Systematic Reviews and MetaAnalyses). ${ }^{28}$

\section{Search Strategy}

Search strategy was determined by the research team in order to respond to the objectives of the systematic review. Two searches were performed in bibliographic databases (PubMed, Embase), dated September 9, 2020. Bibliographic references from the last 10 years were included (January 1, 2011 to September 2020). Search terms included MeSH-controlled terms in PubMed and EMtree in Embase. The following terms were used: "adherence" AND "naltrexone".

\section{Eligibility Criteria}

The studies included in the systematic review meet the following inclusion criteria. 1) Published from January 1, 2011 to September 2020. 2) Study participants were over 18 years. 3) Only included human studies. 4) Studies evaluated naltrexone treatment in alcohol use disorder and opioid use disorder. Although naltrexone has already been approved as a treatment for obesity and overweight, it is a drug that combines naltrexone hydrochloride and bupropion hydrochloride and its use has been extended to different disorders such as compulsive sexual behavior disorder, gambling, kleptomania and other behavioral addictions. In this report, we have decided to arrange a comprehensive review on the use and adherence of naltrexone in substance use disorders patients (specifically in AUD and OUD due to drug data sheet). ${ }^{29-33} 5$ ) Studies evaluated strategies that improve adherence to naltrexone, globally understood as the time in which the study participants have maintained the treatment and had remained in the study. 6) Studies were published in English. 7) Randomized clinical trial, meta-analyses, systematic 
reviews, cohort studies, case-control studies and observational studies are included.

Letters to the editor, clinical cases, conference presentations and poster-based articles have been excluded.

\section{Review Procedures}

RefWorks ProQuest was used as bibliographic references manager. Two reviewers (VP and MM) implemented an independent screening, by title and abstract, of all the citations identified in the bibliographic search.

Articles were removed from the review for the following reasons: not related to naltrexone, participants did not meet criteria for AUD and/or OUD, according to DSM-5 criteria, failure to address treatment adherence in AUD and/or OUD, case series, poster compendia and use of naltrexone in other addictive and mental disorders. ${ }^{3}$

Subsequently, three reviewers (VP, MM and LG) independently reviewed the studies.

Divergences between reviewers were discussed until consensus was accomplished.

\section{Data Extraction}

The following information was extracted from the studies included in the review: first author, publication year, study design, study population, type, setting, aim, duration, intervention, outcomes of the study, intention-to-treat analysis, and study based on patient preferences.

\section{Results}

A total of 133 unique citations were identified through the electronic database searches. Firstly, reports were screened by title, so 74 potentially eligible articles remained. Reasons to exclude them by title were: reports were not related with naltrexone, AUD and/or OUD; reports did not evaluate adherence or did not meet inclusion criteria of the review. Secondly, reports were screened by abstract and 53 articles remained. Reasons to remove articles by abstract were the same than in previous step. Case reports and poster-based publications were excluded in both procedures due to not being a suitable study design for the review. A total of 53 articles were fully analyzed and up to 17 of them were removed because of not being suitable for the aim of the review, not evaluating study population of the review and not meeting criteria for study included in the review. Finally, a total of 36 studies were included and analyzed in the systematic review. 16 studies corresponded to patients with alcohol use disorder and 20 studies to patients with opioid use disorder (Figure 1).

\section{Description of the Studies}

To analyze the available evidence on adherence to naltrexone in people with a substance use disorder, the studies were classified into two large groups: those conducted in people with opioid use disorder, and those conducted in people with alcohol use disorder.

\section{Studies Conducted in Patients with Opioid Use Disorder}

Table 1 Describes a total of 20 studies performed in people with an opioid use disorder that have finally been selected for this review.

The duration range of the different reviewed studies is 15 days -5 years.

\section{Adherence and Predictors}

Regarding treatment initiation, one study observed that adherence to XR-NTX was higher after prior detoxification with naltrexone than with buprenorphine. ${ }^{34}$

On long-term adherence, the study of the longest duration found that adherence to XR-NTX increased significantly by $89 \%$ from Year 1-Year 5, when patients are facilitated in the administration of the treatment. ${ }^{35}$

A total of 3 studies aimed to evaluate possible medical variable predictors of adherence to NTX. Elderly patients and those who were tested for HIV were more likely to obtain two or more consecutive doses of extended-release naltrexone (XR-NTX). ${ }^{36}$ Moreover, the duration of opioid addiction as well as alcohol consumption have also been considered independent predictors for longer-term retention in treatment. ${ }^{37}$ On the other hand, having a mental illness or having used emergency services in the previous year were related to poorer adherence. ${ }^{36}$ No personality characteristics have been found to be associated with higher adherence rates. ${ }^{38}$

\section{Combination of Naltrexone with Other Interventions}

Regarding contingency programs, studies have shown that when complementing treatment with XR-NTX, have generally been shown to be effective compared to drug treatment alone. ${ }^{24,39}$ In addition, employment-based reinforcement systems, have also shown to improve adherence to XR-NTX. ${ }^{40}$ Employment-based contingency or reinforcement programs were similar across studies, and consisted of earning a weekly wage directly from work or attending a therapeutic worksite on a daily basis where 


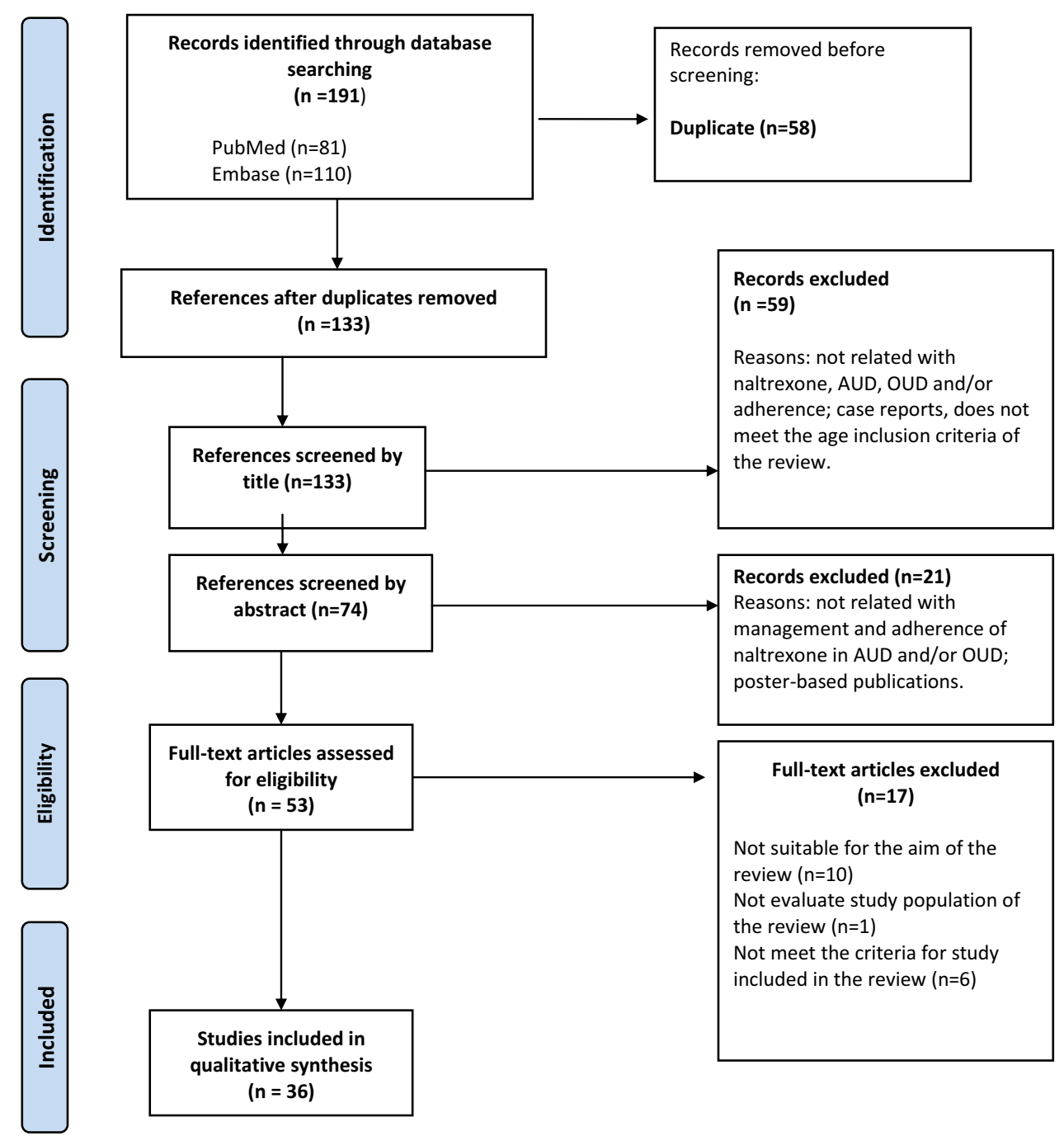

Figure I Flowchart of included studies.

they were paid by the hour to achieve goals in training programs. With oral naltrexone, the use of contingency programs in addition to treatment compared to using the drug alone resulted in better adherence rates in studies of 26 weeks duration, but no significant differences were found when extending follow-up to 12 months. ${ }^{41,42}$

Furthermore, a beneficial effect of adjuvant psychotherapy as a promoter of adherence has been observed in people with OUD who initiate treatment with XR$\mathrm{NTX}^{43}$ Specifically, in low-severity heroin users $(\leq 5$ bags per day or $\leq 200 \mathrm{mg}$ of morphine equivalents), the behavioral therapy combined with XR-NTX has shown to improve long-term treatment retention rates. ${ }^{44}$

\section{Special Populations}

Studies evaluating adherence to XR-NTX in prisoners have been reviewed; those conducted in prisons did not find differences in adherence when evaluating the effectiveness of XR-NTX alone or in conjunction with patient navigation in jail inmates. ${ }^{45}$ Studies also conclude that people on parole or probation are less likely to complete XR-NTX induction and may need additional supports or modifications for induction procedures to be successful. ${ }^{46}$

\section{Comparison of Naltrexone to Placebo or Other Medication}

Studies comparing adherence between NTX and different treatment options including placebo show disparate results as shown in Table 1. In a follow-up study of 24 weeks, comparing the use of XR-NTX with naloxonebuprenorphine, differences in adherence to both treatments were not found ${ }^{47}$ In another study of the same duration, did show better adherence vs. placebo. ${ }^{48}$ The remaining 


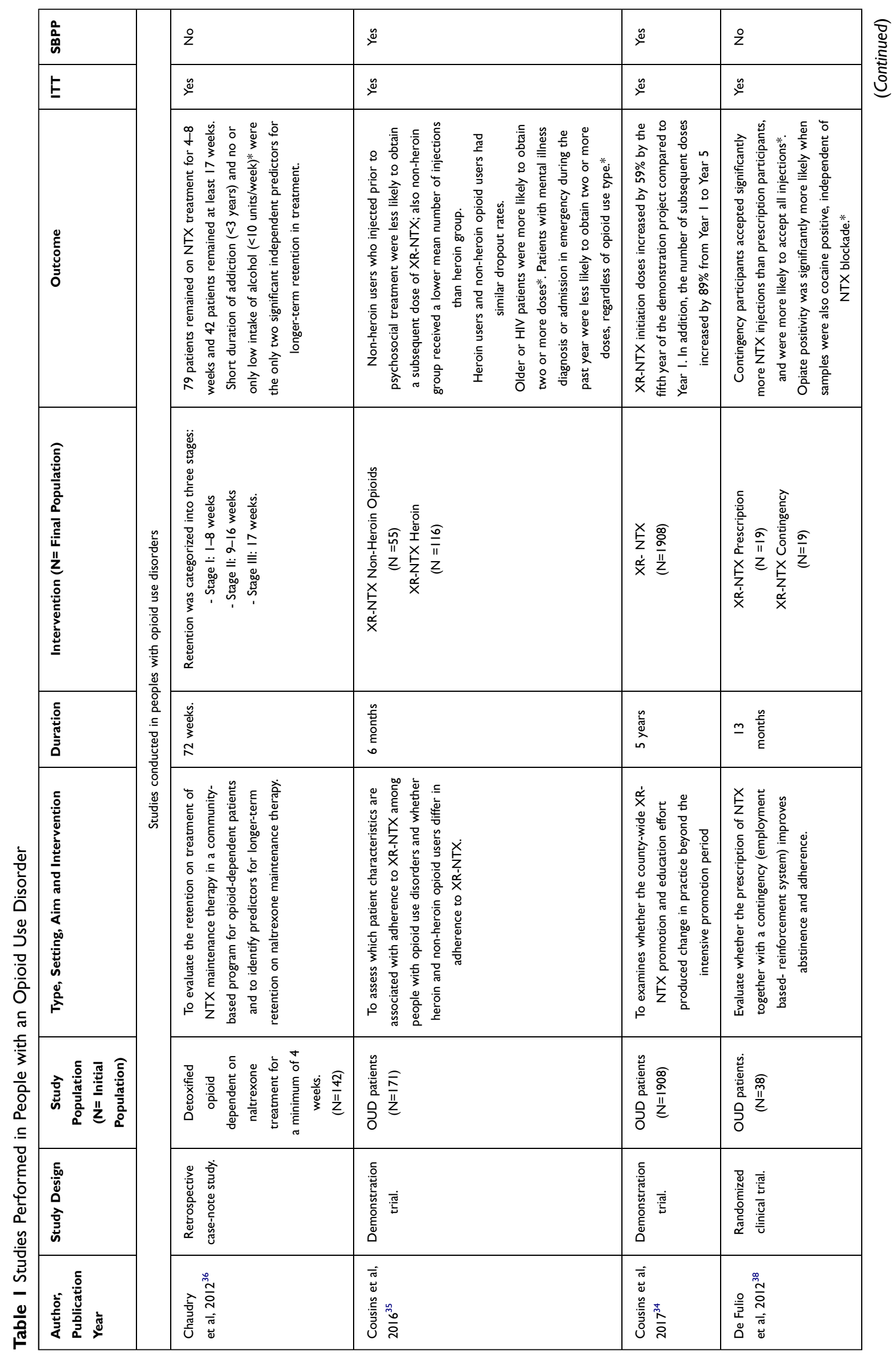




\begin{tabular}{|c|c|c|c|c|c|}
\hline $\begin{array}{l}\frac{a}{0} \\
\text { ôn }\end{array}$ & zo & zo & zo & $\stackrel{0}{z}$ & 우 \\
\hline E & $\stackrel{\tilde{u}}{\tau}$ & $\stackrel{\check{\varpi}}{\tau}$ & zo & $\stackrel{\check{\nu}}{\check{\nu}}$ & $\stackrel{\mathscr{y}}{\tau}$ \\
\hline & 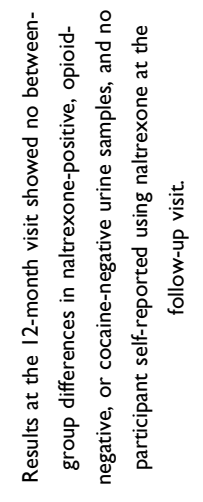 & 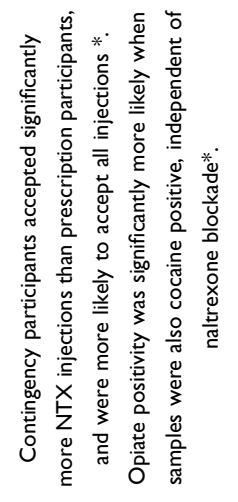 & 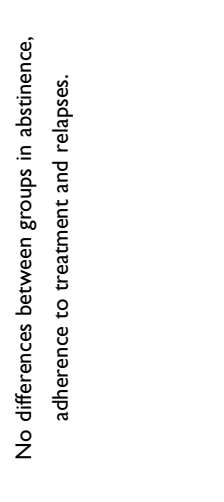 & 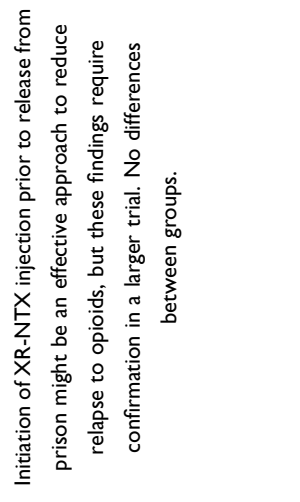 & 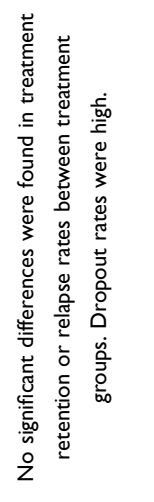 \\
\hline 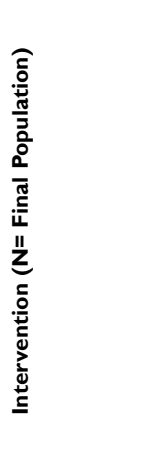 & 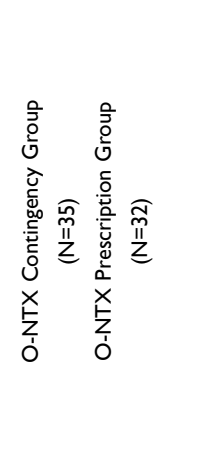 & 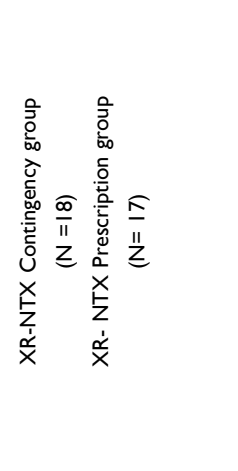 & 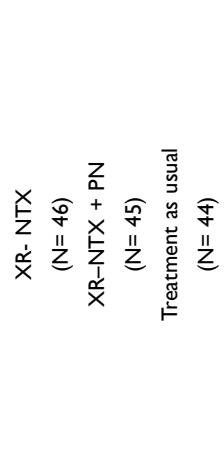 & 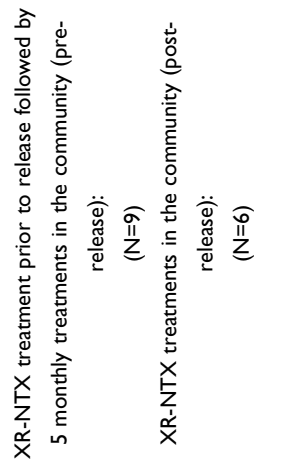 & 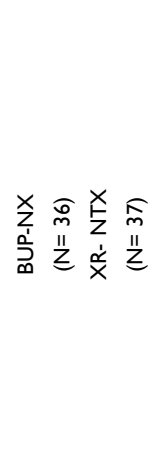 \\
\hline 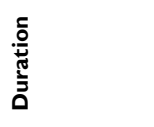 & 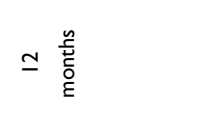 & 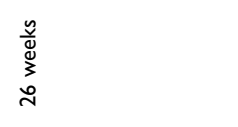 & 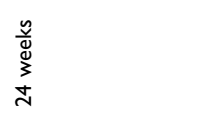 & 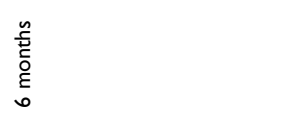 & 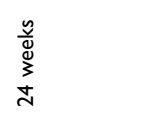 \\
\hline 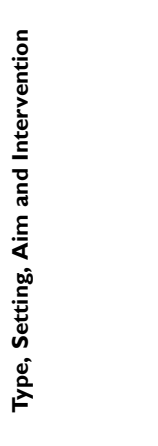 & 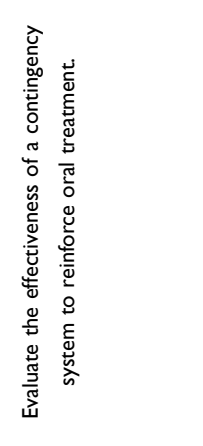 & 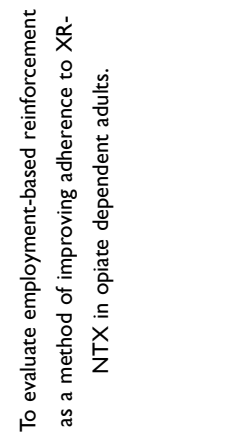 & 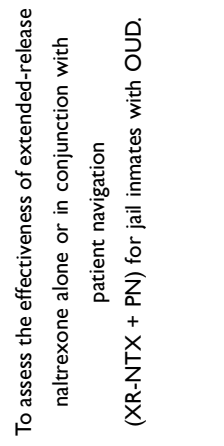 & 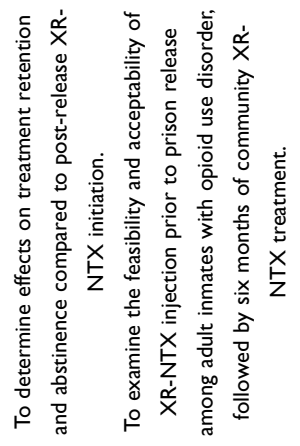 & 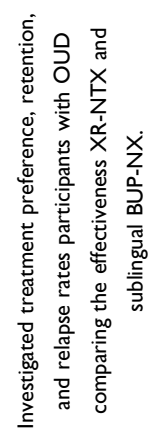 \\
\hline 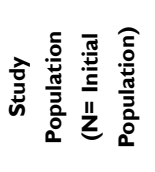 & 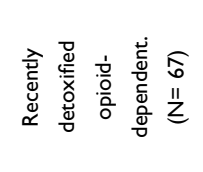 & 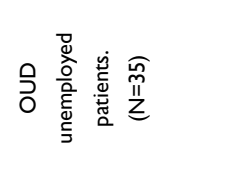 & 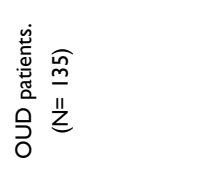 & 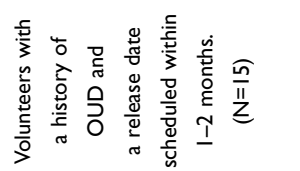 & 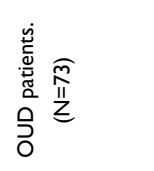 \\
\hline 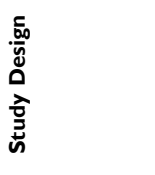 & 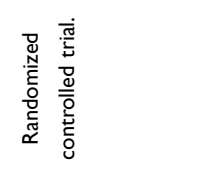 & 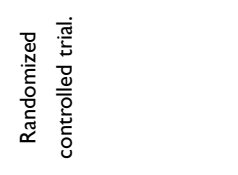 & 离 & 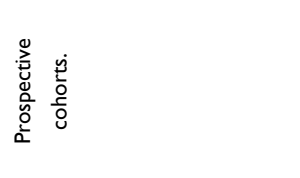 & 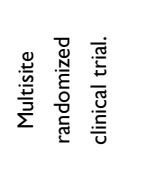 \\
\hline 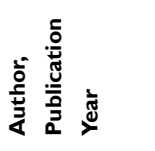 & 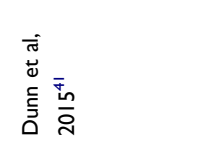 & 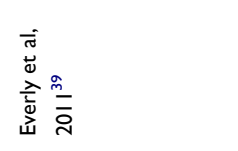 & 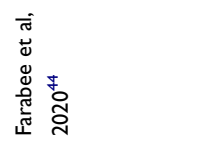 & 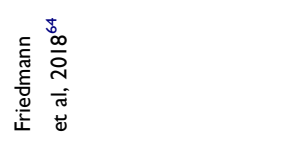 & 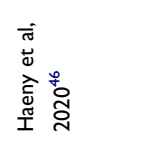 \\
\hline
\end{tabular}




\begin{tabular}{|c|c|c|c|c|}
\hline zo & z̊ & o & $\stackrel{0}{z}$ & $\stackrel{0}{z}$ \\
\hline$\stackrel{0}{\check{0}}$ & $\stackrel{\varrho}{\swarrow}$ & $\stackrel{0}{x}$ & $\mathscr{x}$ & 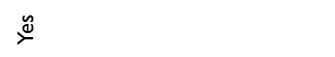 \\
\hline 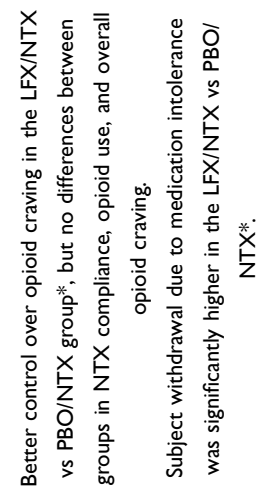 & 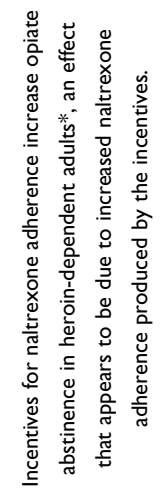 & 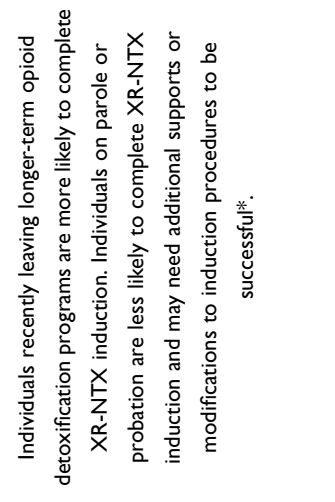 & 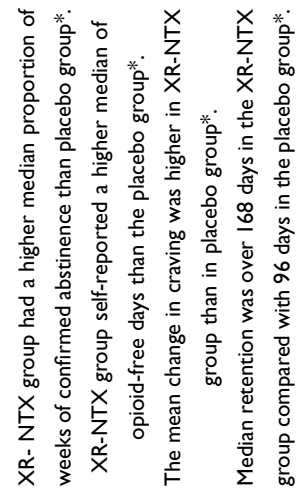 & 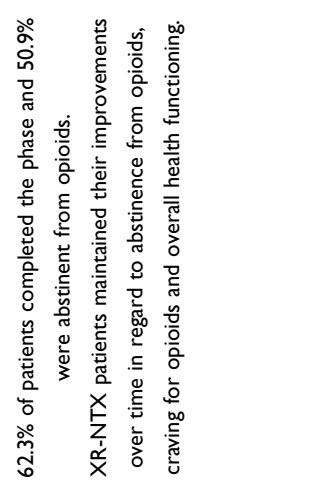 \\
\hline 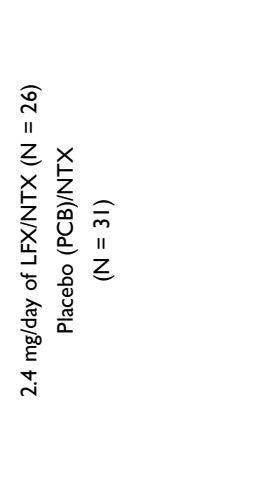 & 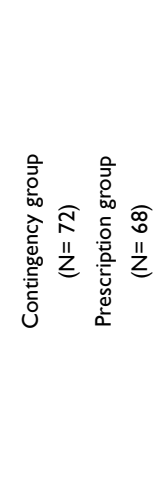 & 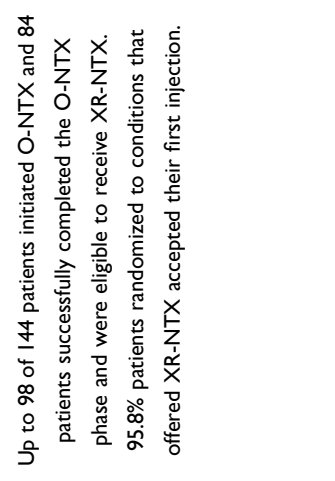 & 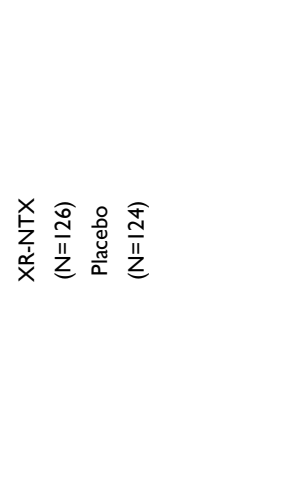 & 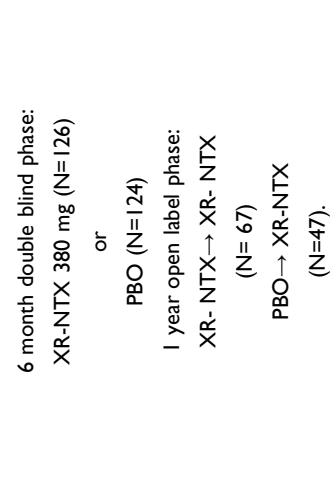 \\
\hline $\begin{array}{l}\stackrel{\tilde{w}}{\mathbb{0}} \\
\stackrel{\Xi}{3} \\
\underline{\simeq}\end{array}$ & 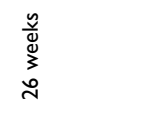 & 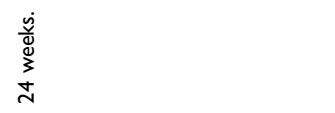 & 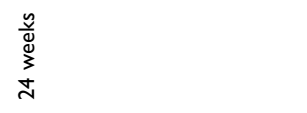 & 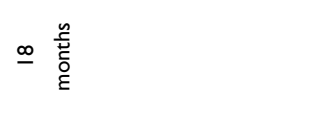 \\
\hline 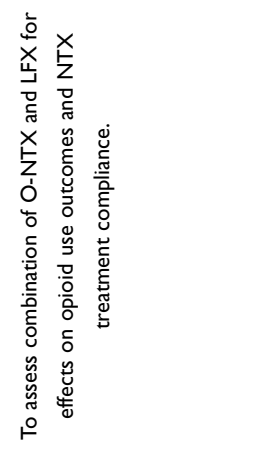 & 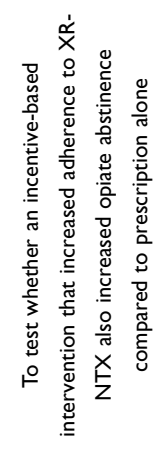 & 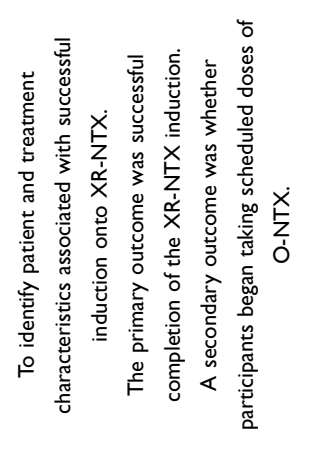 & 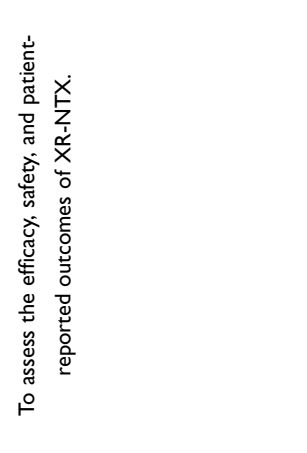 & 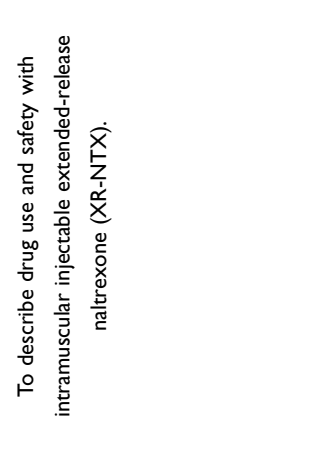 \\
\hline 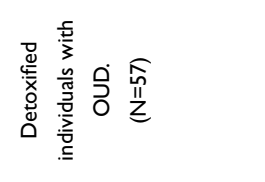 & 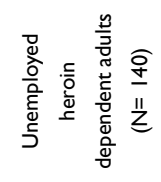 & 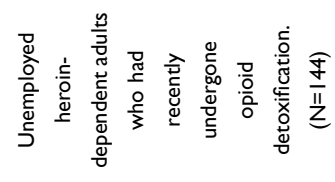 & 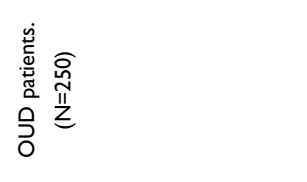 & 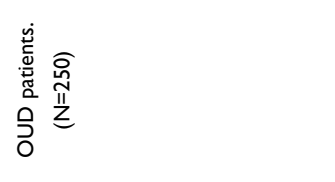 \\
\hline 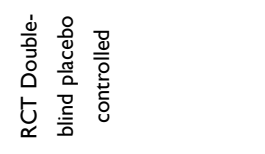 & 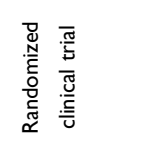 & 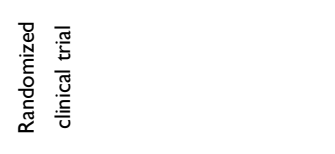 & 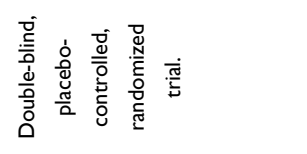 & 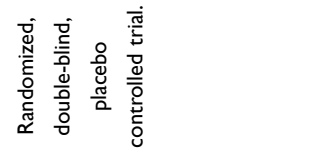 \\
\hline 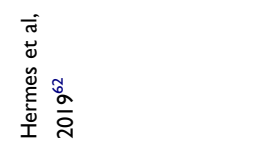 & 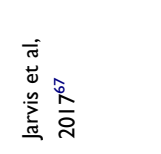 & 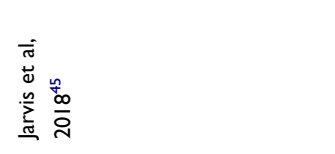 & 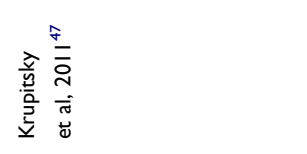 & 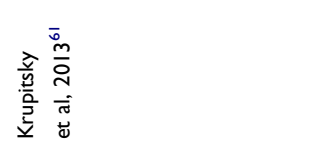 \\
\hline
\end{tabular}




\begin{tabular}{|c|c|c|c|c|c|}
\hline $\begin{array}{l}\frac{a}{a} \\
\vdots \\
\vdots \\
\omega\end{array}$ & $\stackrel{0}{z}$ & z̊ & z̊ & $\stackrel{0}{z}$ & $\stackrel{\circ}{z}$ \\
\hline$E$ & $\stackrel{\check{s}}{\check{s}}$ & ๖્้ & $\stackrel{\mathscr{u}}{\check{u}}$ & $\stackrel{\Xi}{\rightleftharpoons}$ & 을 \\
\hline סัّ & 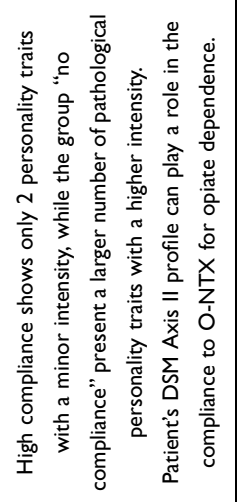 & 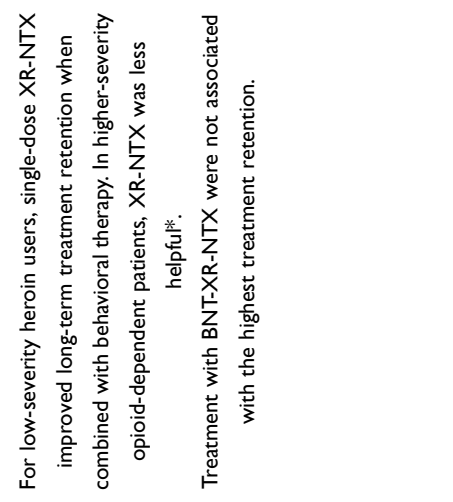 & 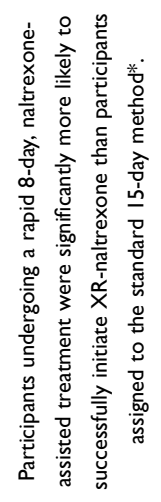 & 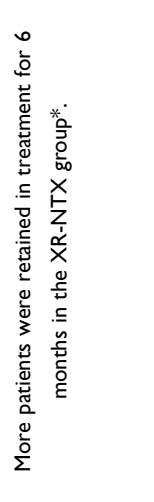 & 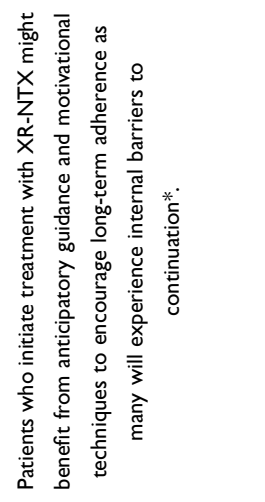 \\
\hline 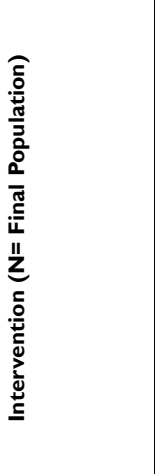 & 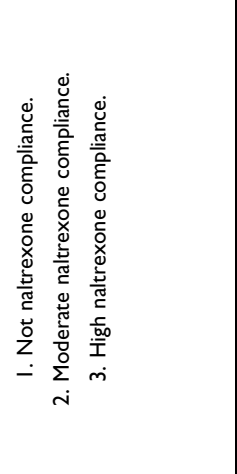 & 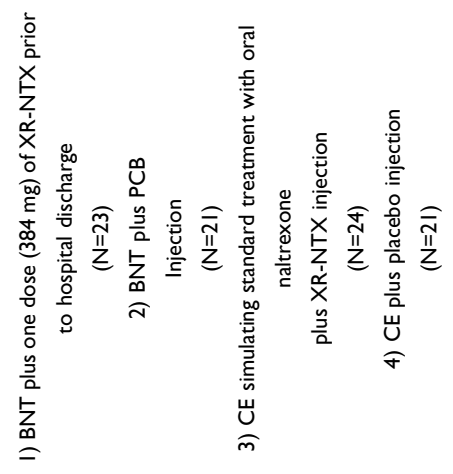 & 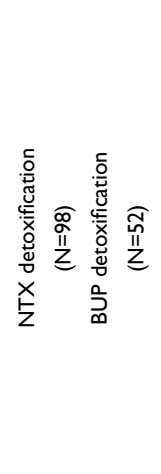 & 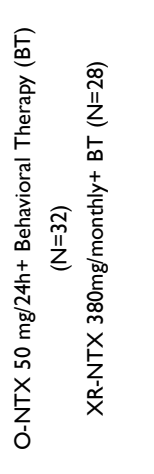 & 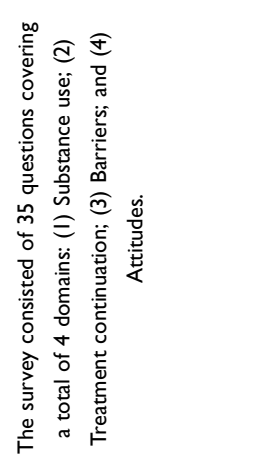 \\
\hline & 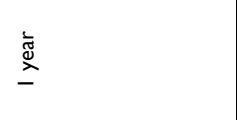 & 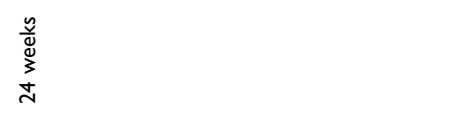 & 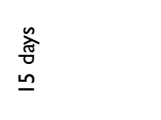 & 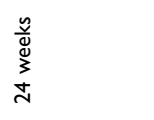 & \\
\hline 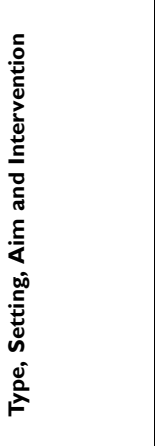 & 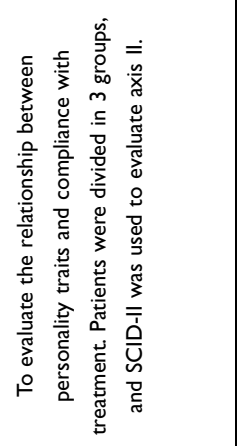 & 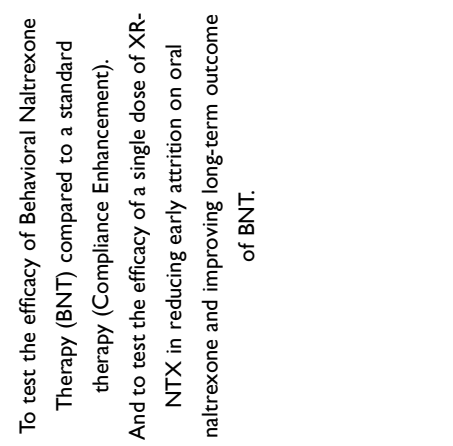 & 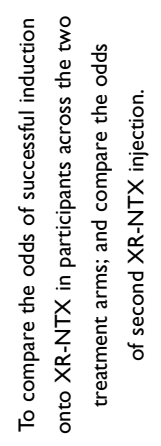 & 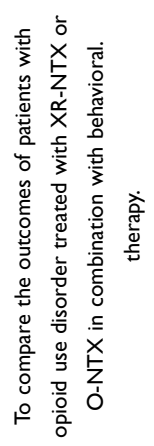 & 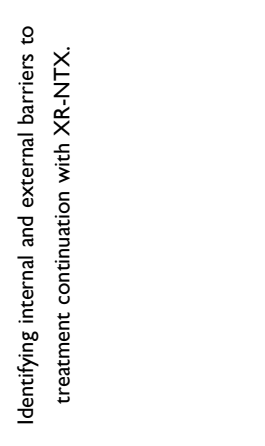 \\
\hline 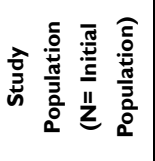 & 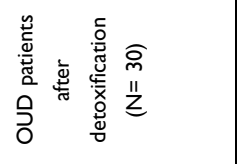 & 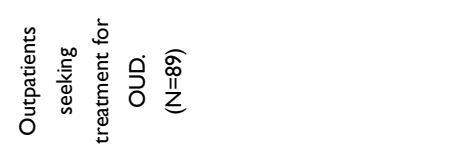 & 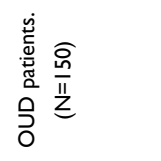 & 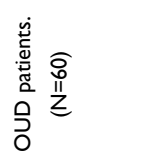 & 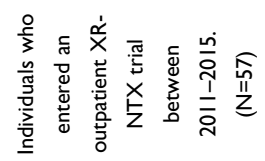 \\
\hline 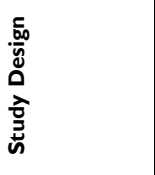 & 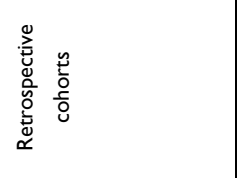 & 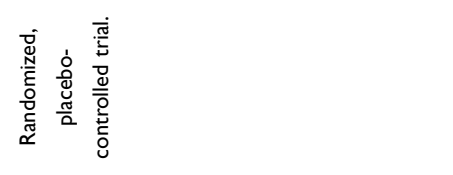 & 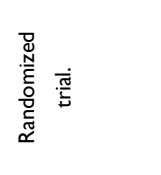 & 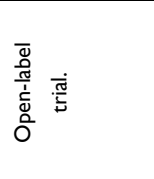 & 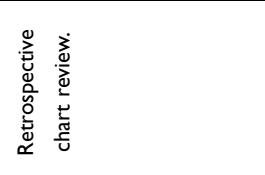 \\
\hline 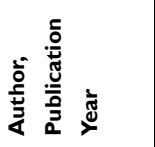 & 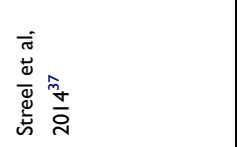 & 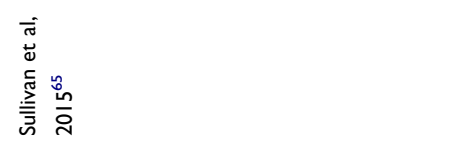 & 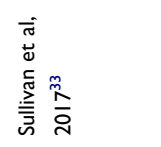 & 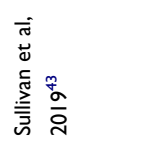 & 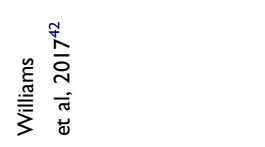 \\
\hline
\end{tabular}




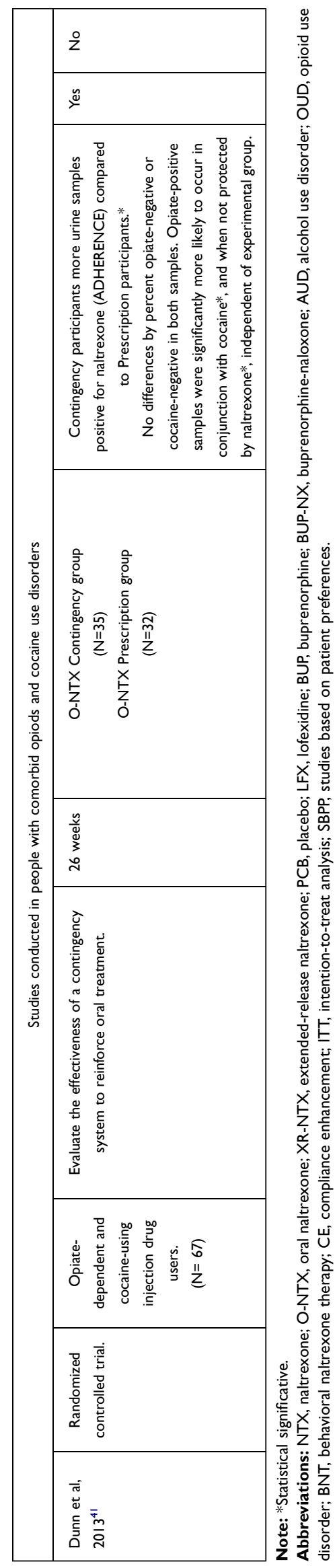

studies did not perform direct comparisons between two treatment options to compare adherence.

\section{Studies Conducted in Patients with Alcohol Use Disorder}

Table 2 Describes a total of 16 studies focused on people with an alcohol use disorder that have been selected for this review.

\section{Adherence and Predictors}

The follow-up period of the different studies focused on adherence to naltrexone in alcohol users has ranged from 4-68 weeks. Overall, these studies show that adherence to any treatment for AUD is low across all medications, and as well as that medication non-adherence is a major barrier to naltrexone's effectiveness in a real-life treatment setting. ${ }^{26,49}$

5 of the total included studies aim to compare the overall adherence to naltrexone based on the formulation of administration, oral or extended-release. Both formulations, which are feasible to initiate prior to discharge for hospital inpatients, have shown high-treatment engagement rates slightly higher than $50 \%$, as well as a significant reduction in alcohol consumption, even in especially vulnerable populations such as people living with HIV. In addition, both O-NTX and XR-NTX have proved to be safe and efficient. ${ }^{50}$ Despite the above, XRNTX in a primary care setting has significantly shown to be more effective, feasible, and cost-effective than O-NTX. ${ }^{51}$ Furthermore, for patients with comorbid opioid misuse who are in treatment for AUD, XR-NTX could enhance treatment adherence. ${ }^{27}$

Barriers to adherence in people with AUD included younger age, self-decision, emotional factors, adverse events greater drinking severity, dissatisfaction with the treatment and session frequency and lack of perceived benefit. Furthermore, the reviewed studies identify barriers to adherence that they classify as those amenable to change including distance and transportation issues, fear of injections, belief that alcohol use does not warrant pharmacotherapy and those not amenable to change as interaction of XR-NTX with another medication regimen. ${ }^{25,52}$

\section{Combination of Naltrexone with Other Interventions}

A total of 3 of the reviewed studies evaluate the benefit of enhancing pharmacological treatment with mobile 


\begin{tabular}{|c|c|c|c|c|c|c|c|}
\hline $\begin{array}{l}\frac{a}{2} \\
\hat{w}\end{array}$ & & zo & zo & $\stackrel{0}{z}$ & 울 & zo & $\stackrel{\circ}{z}$ \\
\hline$\underline{\mathbf{E}}$ & & $\stackrel{\Xi}{\check{\Xi}}$ & zo & 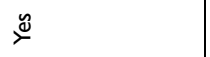 & $\stackrel{\check{\varpi}}{\nsim}$ & zo & 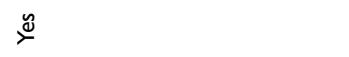 \\
\hline 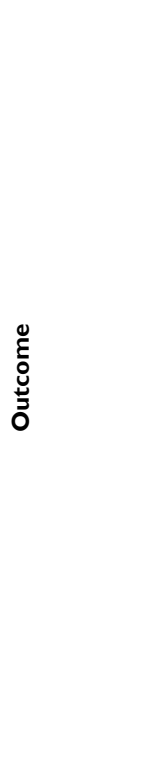 & 音 & 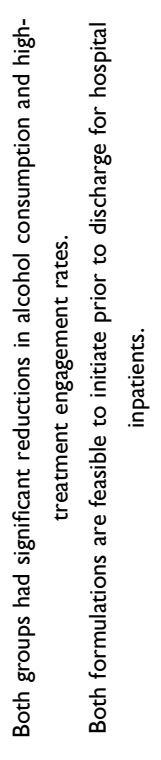 & 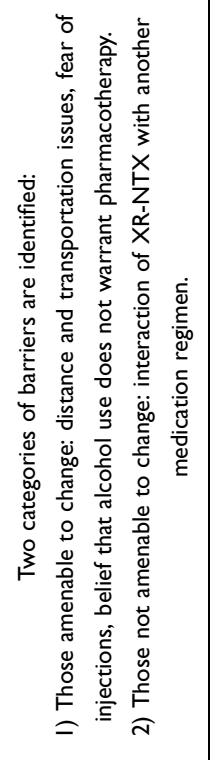 & 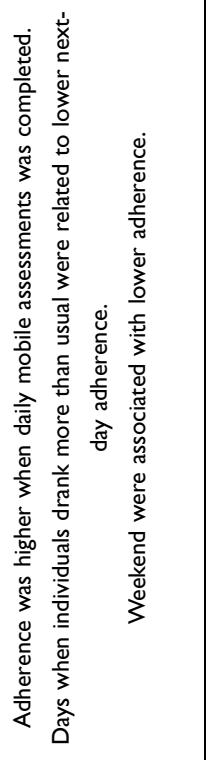 & 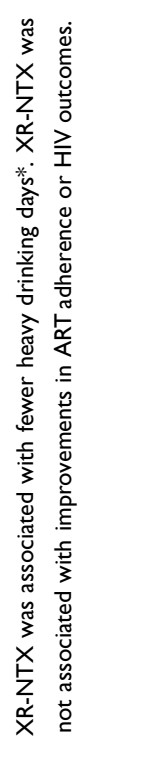 & 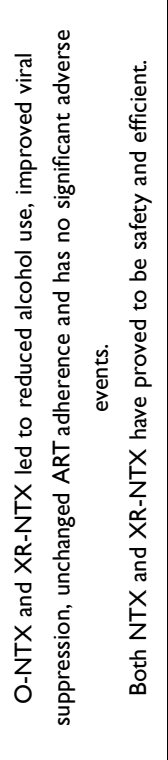 & 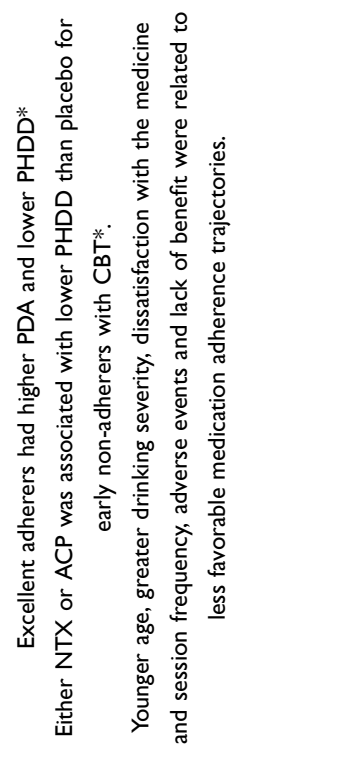 \\
\hline 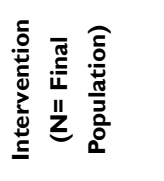 & 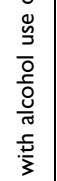 & 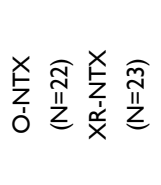 & 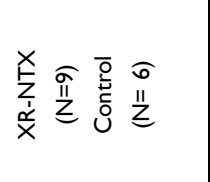 & 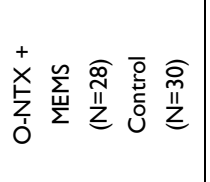 & 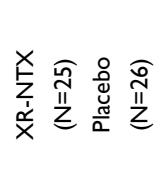 & 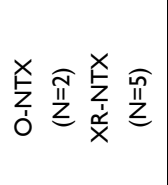 & 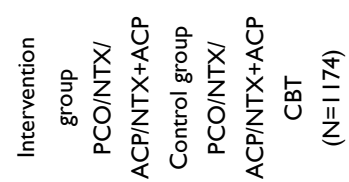 \\
\hline בั & 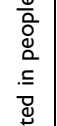 & 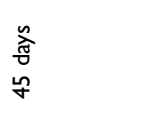 & 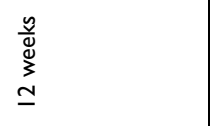 & $\begin{array}{l}\frac{\tilde{v}}{\mathrm{v}} \\
\vdots \\
\infty \\
\infty\end{array}$ & 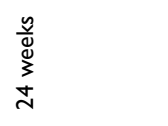 & & 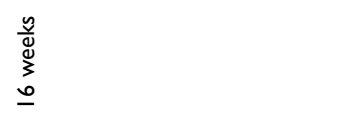 \\
\hline 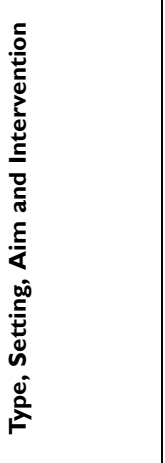 & 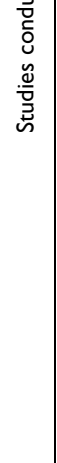 & 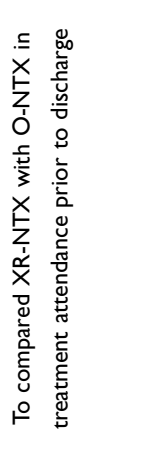 & 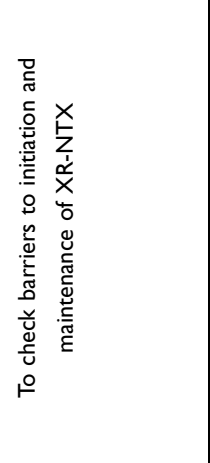 & 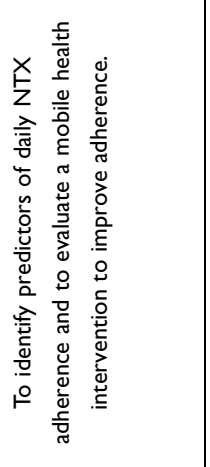 & 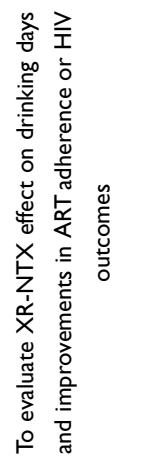 & 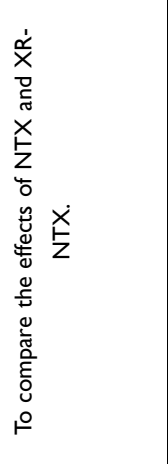 & 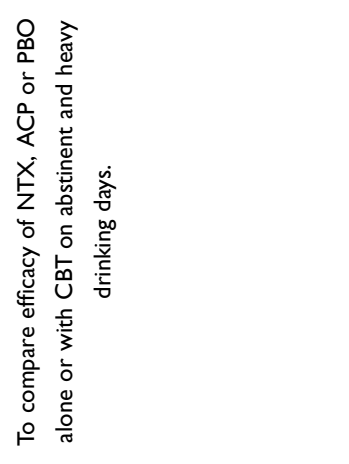 \\
\hline 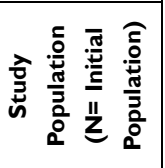 & & 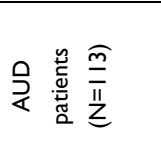 & 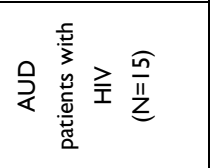 & 虽总总 & 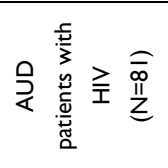 & 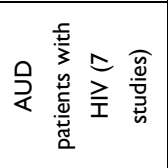 & 虽总产 \\
\hline 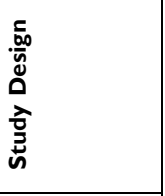 & & 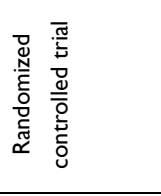 & 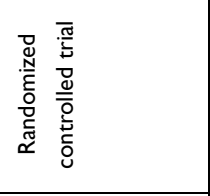 & 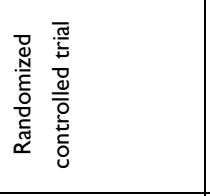 & 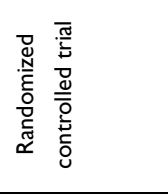 & 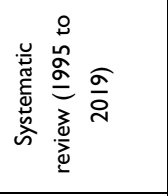 & 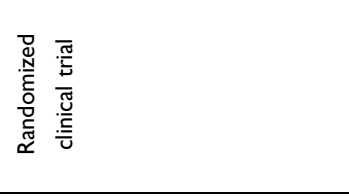 \\
\hline 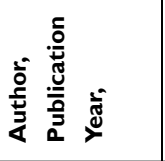 & & 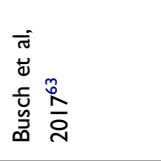 & 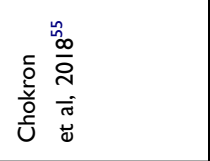 & 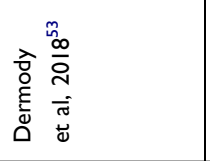 & 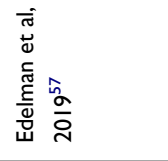 & 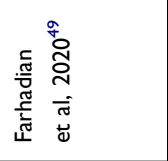 & 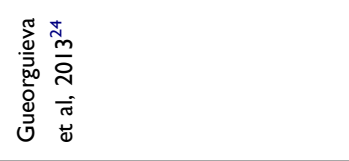 \\
\hline
\end{tabular}




\begin{tabular}{|c|c|c|c|c|c|c|}
\hline 울 & $\stackrel{\mathscr{\varpi}}{\check{\sigma}}$ & $\stackrel{\circ}{z}$ & 으 & $\stackrel{\circ}{z}$ & zo & $\stackrel{\mathscr{y}}{\tau}$ \\
\hline$\stackrel{\check{\nu}}{\check{\nu}}$ & 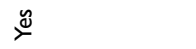 & $\stackrel{\check{\Xi}}{\check{\nu}}$ & $\overbrace{\check{\nu}}^{\check{\nu}}$ & $\stackrel{\check{\varpi}}{\nsim}$ & $\stackrel{\check{\nu}}{\nu}$ & $\stackrel{\check{\Xi}}{\check{\nu}}$ \\
\hline 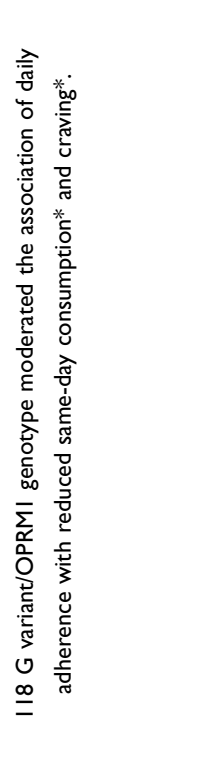 & 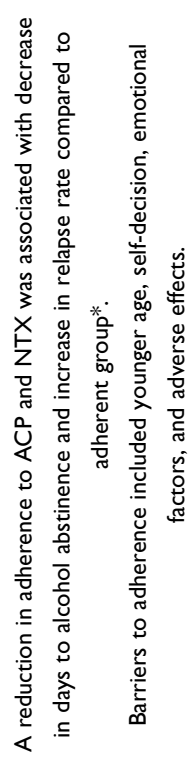 & 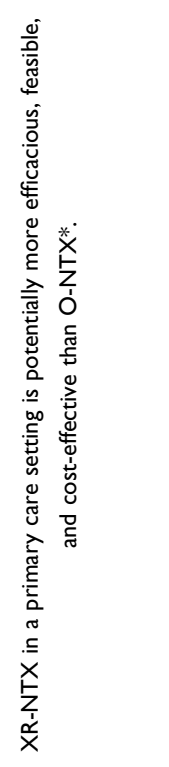 & 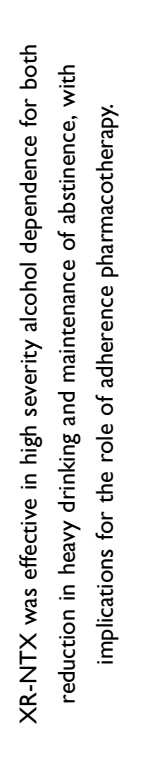 & 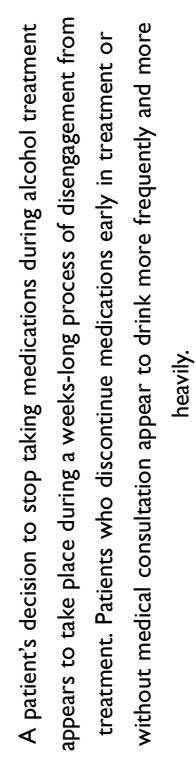 & 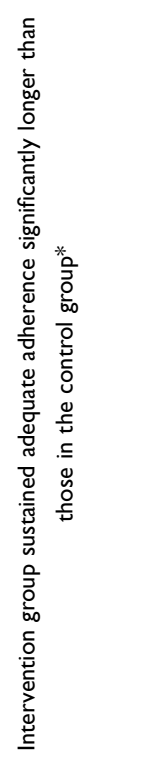 & 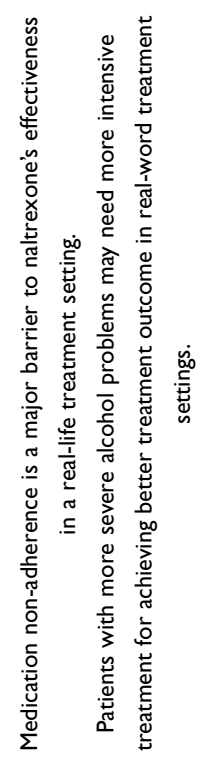 \\
\hline 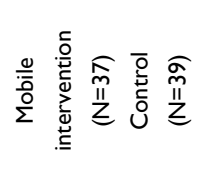 & 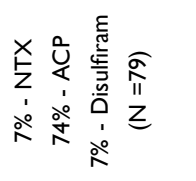 & 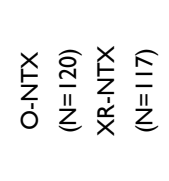 & 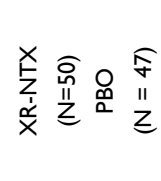 & 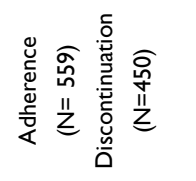 & 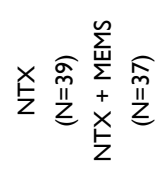 & 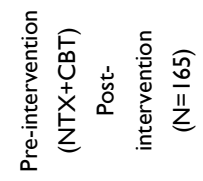 \\
\hline $\begin{array}{l}\stackrel{\tilde{y}}{\mathbb{w}} \\
\sum_{\infty} \\
\infty\end{array}$ & 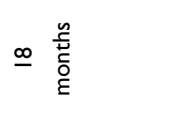 & 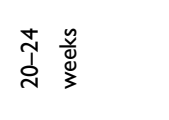 & 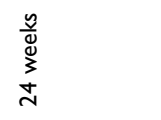 & 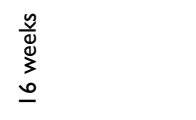 & $\begin{array}{l}\stackrel{\tilde{s}}{\mathbb{\Xi}} \\
\sum_{\infty}^{3} \\
\infty\end{array}$ & $\begin{array}{l}\underline{y} \\
\stackrel{\Xi}{\Xi} \\
3 \\
\underline{0}\end{array}$ \\
\hline 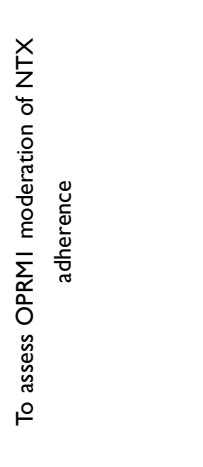 & 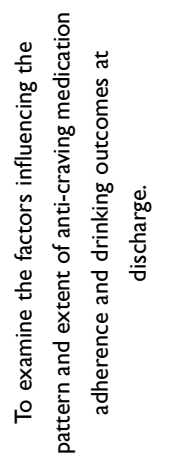 & 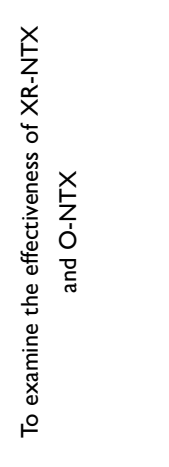 & 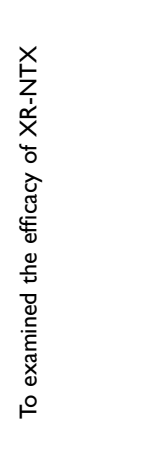 & 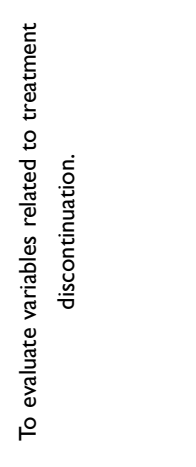 & 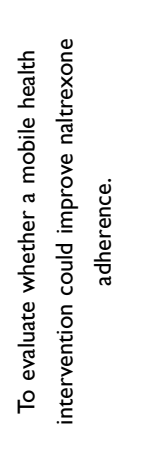 & 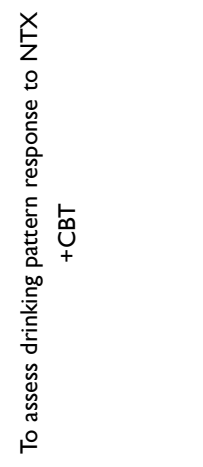 \\
\hline 号总总 & 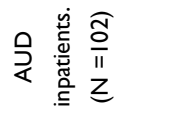 & 号喜亳 & 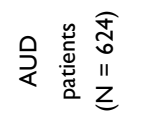 & 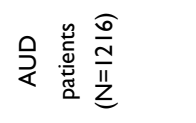 & 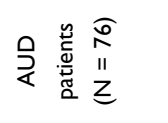 & 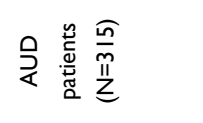 \\
\hline 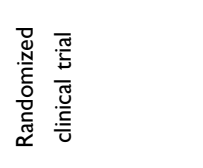 & 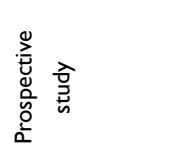 & 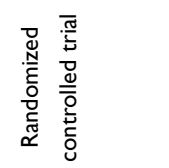 & 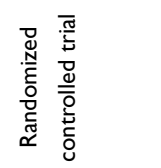 & 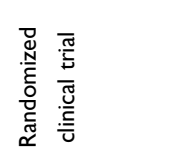 & 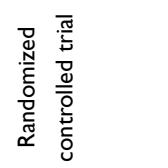 & 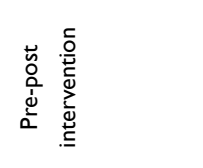 \\
\hline 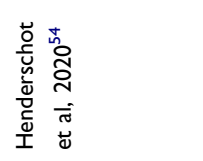 & 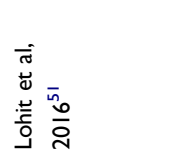 & 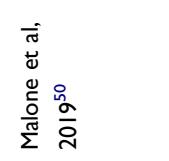 & 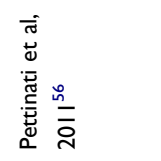 & 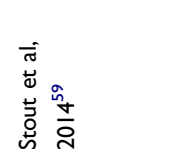 & 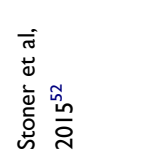 & 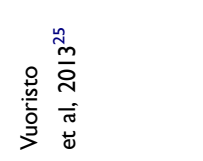 \\
\hline
\end{tabular}




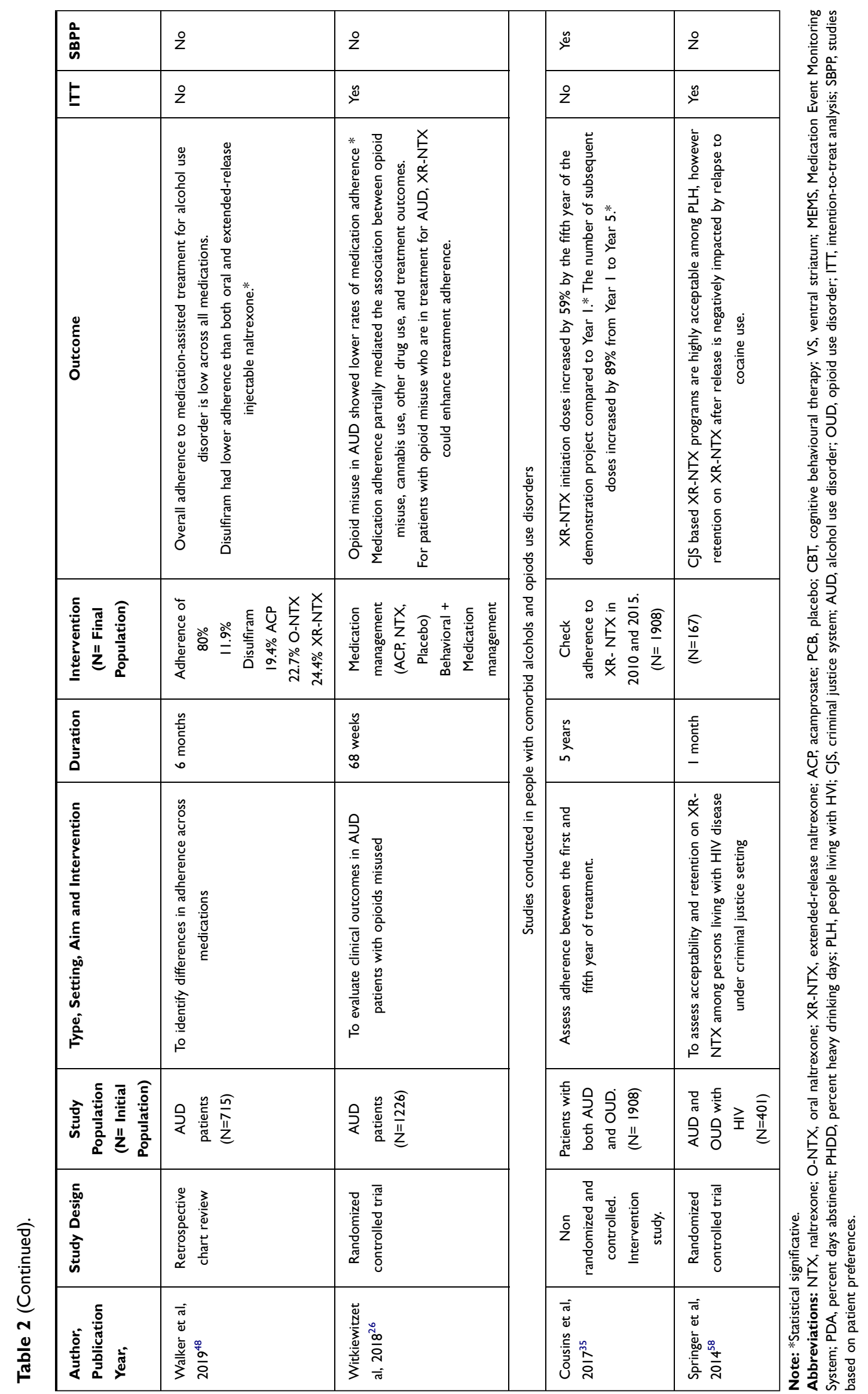


applications to remember and improve adherence. These studies support that complementing the usual pharmacological treatment with telematic resources makes it easier for patients to maintain adequate adherence significantly longer than those who have not had access to mobile application devices. ${ }^{53}$ On the one hand, studies show that adherence was higher when daily mobile assessments were completed, and on the other hand, it was shown a lower next-day adherence in days when individuals drank more than usual as well as weekends ${ }^{54}$ Besides, one of the studies reviewed aimed to assess OPRM1, the $\mu$-opioid receptor gene, moderation of NTX daily adherence, finding that $118 \mathrm{G}$ variant/ OPRM1 genotype significantly moderated the association of daily adherence with reduced same-day consumption and craving. ${ }^{55}$

3 studies assess drinking pattern in response to cognitive therapy added to usual pharmacological treatment. These confirm that excellent adherers to cognitive interventions had significantly higher percent days abstinent (PDA) and lower percent heavy drinking days (PHDD). ${ }^{56}$

\section{Special Populations}

Another of the reviewed studies aims to assess acceptability and retention on XR-NTX among people living with HIV under criminal justice setting pointing to a high acceptable among this group of population. However, retention on XR-NTX programs remained low after release and was negatively impacted by relapse to cocaine use.

\section{Comparison of Naltrexone to Placebo or Other Medication}

Studies comparing adherence between NTX and a placebo control intervention conclude that NTX, specifically the $\mathrm{XR}$ formulation, is significantly more effective in high severity alcohol, and emphasize its implications for the role of pharmacological adherence in people with AUD. ${ }^{57,58}$

2 studies specifically assess adherence to NTX compared to other drugs indicated for patients with AUD. Adherence to medication-assisted treatment for alcohol use disorder is low across all medications. ${ }^{49}$ Within specific treatments, disulfiram has shown to have significantly lower adherence than both oral and extended-release injectable NTX. ${ }^{59}$ Moreover, a reduction in adherence to acamprosate (ACP) and NTX was significantly associated with decrease in days to alcohol abstinence, and increase in relapse rate compared to adherent groups. ${ }^{52}$

Finally, people with a comorbid OUD show significantly lower rates of medication adherence. ${ }^{27}$ In addition, in this specific group of population, medication adherence partially mediates the association between opioid misuse, cannabis use, other drug use, and treatment outcomes. ${ }^{27}$

Studies conclude that patients used to decide to stop taking medications during a weeks-long process of disengagement from treatment. Patients who discontinue medications early in treatment or those without medical consultation appear to drink more frequently and more heavily and, therefore, less favorable medication adherence trajectories seem to be related to worst outcomes. ${ }^{60}$

\section{Discussion}

The studies included in this review focus on the use of naltrexone for patients with alcohol use disorder or opioid use disorder, which are the disorders for which its use has been approved to date. ${ }^{10-13,15}$

To assess the efficacy of naltrexone in patients with opioid use disorder, treatment with XR-NTX at a dose of $300 \mathrm{mg}$ was shown to be effective in blocking opioid agonist challenge effects. ${ }^{61}$ The results of this review have documented that monthly injectable naltrexone is not always favorable compared to other treatment options. We have not found enough studies with a long follow-up time to support the superiority of this treatment over the oral formulation.

In patients with OUD, this alternative has only been shown to be superior to placebo, but no buprenorphine ${ }^{47,48}$ In patients with AUD, treatment with naltrexone, both oral and extended-release, has achieved better adherence rates than treatment with disulfiram. ${ }^{49}$

On the other hand, although oral naltrexone has obtained better results in adherence than placebo, the same has not occurred with XR-NTX ${ }^{25,57,58}$ This suggests that in addition to the form of administration, there may be other factors involved in adherence.

The data available to date on the benefits that naltrexone can offer in terms of improving adherence are scarce and correspond to studies with a maximum duration of 26 weeks. Those studies of 68 weeks conducted with opioids are designed for evaluating adherence in alcohol consumers, and are therefore insufficient. ${ }^{27}$

Several studies focus on evaluating the effect on adherence of using additional measures to pharmacological treatment, such as psychotherapy, contingency systems or 
job-based reinforcement or the mobile reminder and monitoring systems. $^{24,25,39-41,44 .}$

In patients with OUD, the results among the different studies are not homogeneous. With respect to psychotherapy, patients who received this intervention in addition to pharmacological treatment did have better adherence to treatment than those who did not undergo psychotherapy. ${ }^{43,44}$ Contingency or reinforcement systems were not effective in improving adherence as an additional measure to treatment in all studies. The studies by Dunn et al using oral naltrexone found improvements in adherence associated with a contingency system at 26 weeks of follow-up, but the results were not maintained at 12 months ${ }^{41,42}$ On the other hand, studies using XR-NTX did find benefits of using cost-effective job-based reinforcement system to improve adherence over not using it. However, the sample size of these studies is small. ${ }^{39,40}$

In patients with AUD, the use of CBT in addition to naltrexone treatment had different results in different studies $^{25,26}$ However, with the mobile reminder and monitoring system, intervention group sustained adequate adherence significantly longer than those in the control group. ${ }^{53}$

Other additional predictors of good adherence have also been identified, such as having recently visited the emergency room, having HIV, or having recently completed an opioid detoxification program. ${ }^{36,47}$ As barriers limiting adherence have also been identified, it would be interesting to take into account these interventions when designing programs aimed at improving adherence to NTX in substance users. ${ }^{25,52}$

These results reinforce the idea that in this group of patients, adherence depends on variables beyond the mere pharmacological treatment. ${ }^{56}$

Some of the studies included in this review evaluated, in addition to adherence to naltrexone, alcohol or opioid abstinence or relapse rates. The results on opioid abstinence associated with naltrexone treatment are also inconclusive. Of the studies included in this review, not all found significant differences. ${ }^{40-42,45,48,62,63}$ One study assessed the effect of the combination of naltrexone with lofexidine with respect to naltrexone associated with placebo, and found that the combination with lofexidine was favorable with respect to craving control but did not provide improvements in abstinence from opioid use. ${ }^{63}$ These results differ from some previously found. ${ }^{10}$

In alcohol-consuming patients, despite having adherence rates around $50 \%$, both oral NTX and XR have been shown to be safe and effective drugs in reducing alcohol consumption even in populations with comorbidity. ${ }^{50,59,64}$

\section{Limitations}

This search is limited to studies included in PubMed or Embase in the last 9 years, so information may have been missed. Nevertheless, broad search criteria have been used to try to collect as much evidence as possible.

Most of the included studies do not take into account patients' preferences when choosing the treatment to which they are assigned, but are randomized clinical trials. Although this design improves the internal validity of the study, the results lose external validity because they cannot always be extrapolated to the general population due to the strict inclusion criteria used.

The duration of most studies does not exceed six months which, in a population with chronic disorders such as alcohol or opioid dependence, may be insufficient. However, these follow-up times may be justified by the loss to followup that frequently occurs in this population group.

Son escasos los estudios que realizan una comparación directa entre dos opciones de tratamiento para evaluar la adherencia, y muchos de ellos tienen en cuenta población con consumo de múltiples sustancias, lo que puede incluir variables de confusión en los resultados.

\section{Conclusions}

Naltrexone is an effective treatment alternative for opioid use disorder, but has not demonstrated superiority to other available treatments in terms of adherence.

Furthermore, adherence to NTX for AUD is globally low and, as a consequence, may limit the efficacy of the treatment. The studies reviewed do not find differences in relation to the adherence rate between the different formulations available, but they suggest possible alternatives that could improve adherence, such as mobile devices and adjunctive psychotherapy.

Studies of longer duration and taking into account patient preferences are needed to extrapolate the results obtained.

Given that the use of reinforcement systems has obtained favorable results as an additional strategy to pharmacological treatment, it would be interesting to carry out long-term studies that take into account this type of intervention and to study other psychosocial variables involved. 


\section{Abbreviations}

NIDA, National Institute on Drug Abuse; WHO, World Health Organization; FDA, Food and Drug Administration; AUD, Alcohol Use Disorders; OUD, Opioid Use Disorder; O-NTX, Oral-Naltrexone; PRISMA, Preferred Reporting Items for Systematic reviews and Meta-Analyses; XR-NTX, Extended-Release Naltrexone; PLH, People Living with HIV; CBT, Cognitive Behavioural Therapy; PDA, Percent Days Abstinent; PHDD, Percent Heavy Drinking Days; ACP, acamprosate; ITT, Intention To Treat analysis; SBPP, Studies Based on Patient Preferences.

\section{Acknowledgments}

All authors would like to acknowledge Sandra Quirant Boix for her support in the revision and edition of this paper.

\section{Disclosure}

The authors report no conflicts of interest in this work.

\section{References}

1. Rehm J, Mathers C, Popova S, Thavorncharoensap M, Teerawattananon Y, Patra J. Global burden of disease and injury and economic cost attributable to alcohol use and alcohol-use disorders. Lancet. 2009;373(9682):2223-2233. doi:10.1016/S01406736(09)60746-7

2. Valbuena A, Largo R, Quintero- Gutiérrez J, García- Resa E, Correas J. Comorbidity in hospitalized patients. Clinical and socio-health implications. Addictions. 2001;13(3):297-304.

3. American Psychiatric Association -APA. DSM-5. Diagnostic and Statistical Manual of Mental Disorders. Madrid: Panamericana; 2014

4. Landa N, Fernández- Montalvo J, López- Goñi J, Lorea I Psychopathological comorbidity in alcoholism: a descriptive study. Int J Clin Health Psychol. 2006;6(2):253-269.

5. Scherbaum N, Specka M. Factors influencing the course of opiate addiction. Int $J$ Methods Psychiatr Res. 2008;17(S1):39-44. doi:10.1002/mpr.244

6. NIH Consensus Conference. Effective medical treatment of opiate addiction. JAMA. 1998;280:1936-1943. doi:10.1001/ jama.280.22.1936

7. NIDA. References. National Institute on Drug Abuse website; 2020. Available from: https://www.drugabuse.gov/nidamed-medical-healthprofessionals/treatment/opioid-use-disorder-treatment. Accessed December 30, 2020.

8. Rudd RA, Seth P, David F, Scholl L. Increases in drug and opioidinvolved overdose deaths - United States, 2010-2015. MMWR Morb Mortal Wkly Rep. 2016;65(5051):1445-1452. doi:10.15585/mmwr. $\mathrm{mm} 655051 \mathrm{e} 1$

9. World Health Organization. Global status report on alcohol and health; 2018. Available from: http://www.infocoponline.es/pdf/alco hol-salud.pdf. Accessed December 30, 2020.

10. Balcells M, Gual A. Pharmacotherapy of alcohol withdrawal. New drugs, new concepts. Addictions. 2002;14(1):439-448.

11. Kjome KL, Moeller FG. Long-acting injectable naltrexone for the management of patients with opioid dependence. Subst Abuse. 2011;5:1-9. doi:10.4137/SART.S5452
12. Veilleux JC, Colvin PJ, Anderson J, York C, Heinz AJ. A review of opioid dependence treatment: pharmacological and psycho-social interventions to treat opioid addiction. Clin Psychol Rev. 2010;30:155-166. doi:10.1016/j.cpr.2009.10.006

13. Rösner S, Hackl-Herrwerth A, Leucht S, Vecchi S, Srisurapanont M, Soyka M. Opioid antagonists for alcohol dependence (Review). Cochrane Database Syst Rev. 2010;(12). doi:10.1002/14651858. CD001867.pub3

14. Sadock BJ, Sadock VA, Ruiz P. Psychiatry Synopsis. 11th ed. China: Wolters Kluwer; 2015.

15. Hoa T, Robbins E, Westwood M, Lezama D, Fishman M. Relapse prevention medications in community treatment for young adults with opioid addiction. Substance Abuse. 2016;37(3):392-397. doi:10.1080/08897077.2016.1143435

16. Spanish Agency of Medicines and Health Products [internet]. Madrid: Spanish agency of medicines and health products; 2012 Available from: http://www.aemps.gob.es. Accessed January 1, 2021.

17. Vrijens B, De Geest S, Hughes DA, et al. A new taxonomy for describing and defining adherence to medications. $\mathrm{Br} J$ Clin Pharmacol. 2012;73(5):691-705. doi:10.1111/j.13652125.2012.04167.x

18. Sudakin D. Naltrexone: Not Just For Opioids Anymore. J Med Toxicol. 2016;12(1):71-75. doi:10.1007/s13181-015-0512-x

19. Brewer C, Streel E. Naltrexone implants: a real therapeutic advance both behavioral as well as pharmacological. Addictions. 2003;15 (4):299-308

20. Foster J, Brewer C, Steele T. Naltrexone implants can completely prevent early (1-month) relapse after opiate detoxification: a pilot study of two cohorts with a total of 101 patients with a note on naltrexone blood levels. Addict Biol. 2003;8:211-217. doi:10.1080/ 1355621031000117446

21. Lee J, Friedmann P, Kinlock TW, Nunes E, Gordon M, O’Brien C. Extended-release naltrexone for opioid relapse prevention among opioid-dependent, criminal justice-involved adults. Drug Alcohol Depend. 2015;156(125). doi:10.1016/j.drugalcdep.2015.07.345

22. Brewer C, Streel E. Recent developments in naltrexone implants and depot injections for opiate abuse: the new kid on the block is approaching adulthood. Addictions. 2010;22(4):285-292.

23. Lobmaier P, Kornor H, Kunoe N, Bjorndal A. Sustained-release naltrexone for opioid dependence. Cochrane Database Syst Rev. 2008;2. doi:10.1002/14651858.CD006140.pub2

24. Gueorguieva R, Wu R, Krystal JH, Donovan D, O’Malley SS. Temporal patterns of adherence to medications and behavioral treatment and their relationship to patient characteristics and treatment response. Addict Behav. 2013;38(5):2119-2127. doi:10.1016/j. addbeh.2013.01.024

25. Vuoristo-Myllys S, Lahti J, Alho H, Julkunen J. Predictors of dropout in an outpatient treatment for problem drinkers including cognitive-behavioral therapy and the opioid antagonist naltrexone. J Stud Alcohol Drugs. 2013;74(6):894-901. doi:10.15288/ jsad.2013.74.894

26. Witkiewitz K, Votaw VR, Vowles KE, Kranzler HR. Opioid misuse as a predictor of alcohol treatment outcomes in the combine study: mediation by medication adherence. Alcohol Clin Exp Res. 2018;42 (7):1249-1259. doi:10.1111/acer.13772

27. Moher D, Shamseer L, Clarke M, et al. Preferred reporting items for systematic review and meta-analysis protocols (PRISMA-P) 2015 statement. Syst Rev. 2015;4(1):1. doi:10.1186/2046-4053-4-1

28. Caixàs A, Albert L, Capel I, Rigla M. Naltrexone sustained-release/ bupropion sustained-release for the management of obesity: review of the data to date. Drug Des Devel Ther. 2014;8:1419-1427. doi:10.2147/DDDT.S55587

29. Savard J, Öberg KG, Chatzittofis A, Dhejne C, Arver S, Jokinen J. Naltrexone in compulsive sexual behavior disorder: a feasibility study of twenty men. $J$ Sex Med. 2020;17(8):1544-1552. doi:10.1016/j.jsxm.2020.04.318 
30. Kovanen L, Basnet S, Castrén S, et al. A randomised, double-blind, placebo-controlled trial of as-needed naltrexone in the treatment of pathological gambling. Eur Addict Res. 2016;22:70-79. doi:10.1159/ 000435876

31. Olbrich S, Jahn I, Stengler K. Exposure and response prevention therapy augmented with naltrexone in kleptomania: a controlled case study using galvanic skin response for monitoring. Behav Cogn Psychother. 2019;47(5):622-627. doi:10.1017/S1352465819000213

32. Aboujaoude E, Salame W. Naltrexone: a pan-addiction treatment? CNS Drugs. 2016;30(8):719-733. doi:10.1007/s40263-016-0373-0

33. Sullivan M, Bisaga A, Pavlicova M, et al. Long-acting injectable naltrexone induction: a randomized trial of outpatient opioid detoxification with naltrexone versus buprenorphine. Am J Psychiatry. 2017;174(5):459-467. doi:10.1176/appi.ajp.2016.16050548

34. Cousins SJ, Crèvecoeur-MacPhail D, Kim T, Rawson RA. Los Angeles County hub-and-provider network for promoting the sustained use of extended-release naltrexone (XR-NTX) in Los Angeles County (2010-2015). J Subst Abuse Treat. 2017;85:78-83. doi:10.1016/j.jsat.2017.02.011

35. Cousins SJ, Radfar SR, Crèvecoeur-MacPhail D, Ang A, Darfler K, Rawson RA. Predictors of continued use of extended-released Naltrexone (XR-NTX) for opioid-dependence: an analysis of heroin and non-heroin opioid users in Los Angeles County. J Subst Abuse Treat. 2016;63:66-71. doi:10.1016/j.jsat.2015.12.004

36. Chaudhry ZA, Sultan J, Alam F. Predictors for retention in treatment with a UK community-based naltrexone program for opioid dependence. Psychiatrist. 2012;36(6):218-224. doi:10.1192/pb. bp. 111.035063

37. Streel E, Chenut C, Papageorgiou C, Verbanck P. DSM IV axis II traits can influence compliance to treatment with oral naltrexone: a preliminary study on 30 opiate dependent patients. Addict Behav. 2014;39(1):321-324. doi:10.1016/j.addbeh.2013.08.031

38. DeFulio A, Everly JJ, Leoutsakos JM, et al. Employment-based reinforcement of adherence to an FDA approved extended release formulation of naltrexone in opioid-dependent adults: a randomized controlled trial. Drug Alcohol Depend. 2012;120(1-3):48-54. doi:10.1016/j.drugalcdep.2011.06.023

39. Everly JJ, DeFulio A, Koffarnus MN, et al. Employment-based reinforcement of adherence to depot naltrexone in unemployed opioid-dependent adults: a randomized controlled trial. Addictions. 2011;106(7):1309-1318. doi:10.1111/j.1360-0443.2011.03400.x

40. Dunn KE, Defulio A, Everly JJ, et al. Employment-based reinforcement of adherence to oral naltrexone treatment in unemployed injection drug users. Exp Clin Psychopharmacol. 2013;21(1):74-83. doi: $10.1037 / \mathrm{a} 0030743$

41. Dunn K, DeFulio A, Everly JJ, et al. Employment-based reinforcement of adherence to oral naltrexone in unemployed injection drug users: 12-month outcomes. Psychol Addict Behav. 2015;29 (2):270-276. doi:10.1037/adb0000010

42. Williams AR, Barbieri V, Mishlen K, et al. Long-term follow-up study of community-based patients receiving XR-NTX for opioid use disorders. Am J Addict. 2017;26:319-325. doi:10.1111/ajad.12527

43. Sullivan MA, Bisaga A, Pavlicova M, et al. A randomized trial comparing extended-release injectable suspension and oral naltrexone, both combined with behavioral therapy, for the treatment of opioid use disorder. Am J Psychiatry. 2019;176(2):129-137. doi:10.1176/appi.ajp.2018.17070732

44. Farabee D, Condon T, Hallgren K, McCrady B. A randomized comparison of extended-release naltrexone with or without patient navigation vs enhanced treatment-as-usual for incarcerated adults with opioid use disorder. J Subst Abuse Treat. 2020;117:1-8. doi:10.1016/ j.jsat.2020.108076

45. Jarvis BP, Holtyn AF, Berry MS, et al. Predictors of induction onto extended-release naltrexone among unemployed heroin-dependent adults. J Subst Abuse Treat. 2018;85:38-44. doi:10.1016/j. jsat.2017.04.012
46. Haeny AM, Montgomery L, Burlew AK, et al. Extended-release naltrexone versus buprenorphine-naloxone to treat opioid use disorder among black adults. Addict Behav. 2020;110:106514. doi:10.1016/j.addbeh.2020.106514

47. Krupitsky E, Nunes EV, Ling W, Illeperuma A, Gastfriend DR, Silverman BL. Injectable extended-release naltrexone for opioid dependence: a double-blind, placebo-controlled, multicentre randomised trial. Lancet. 2011;377(9776):1506-1513. doi:10.1016/S01406736(11)60358-9

48. Walker JR, Korte JE, McRae-Clark AL, Hartwell KJ. Adherence across FDA-approved medications for alcohol use disorder in a veterans administration population. J Stud Alcohol Drugs. 2019;80(5):572-577. doi:10.15288/jsad.2019.80.572

49. Farhadian N, Moradi S, Zamanian MH, et al. Effectiveness of naltrexone treatment for alcohol use disorders in HIV: a systematic review. Subst Abuse Treat Prev Policy. 2020;15:24. doi:10.1186/ s13011-020-00266-6

50. Malone M, McDonald R, Vittitow A, et al. Extended-release vs. oral naltrexone for alcohol dependence treatment in primary care $(\mathrm{XON})$. Contemp Clin Trials. 2019;81:102-109. doi:10.1016/j. cct.2019.04.006

51. Lohit K, Kulkarni C, Galgali RB. Factors influencing adherence to anti-craving medications and drinking outcomes in patients with alcohol dependence: a hospital-based study. $J$ Pharmacol Pharmacother. 2016;7(2):72-79. doi:10.4103/0976-500X.184770

52. Stoner SA, Arenella PB, Hendershot CS. Randomized controlled trial of a mobile phone intervention for improving adherence to naltrexone for alcohol use disorders. PLoS One. 2015;10(4):e0124613. doi:10.1371/journal.pone.0124613

53. Dermody SS, Wardell JD, Stoner SA, Hendershot CS. Predictors of daily adherence to naltrexone for alcohol use disorder treatment during a mobile health intervention. Ann Behav Med. 2018;52 (9):787-797. doi:10.1093/abm/kax053

54. Hendershot CS, Dermody SS, Wardell JD, Zaso MJ, Kennedy JL, Stoner SA. OPRM1 moderates daily associations of naltrexone adherence with alcohol consumption: preliminary evidence from a mobile health trial. Alcohol Clin Exp Res. 2020;44(4):983-991. doi:10.1111/acer. 14300

55. Chokron Garneau H, Venegas A, Rawson R, Ray LA, Glasner S. Barriers to initiation of extended release naltrexone among HIV-infected adults with alcohol use disorders. J Subst Abuse Treat. 2018;85:34-37. doi:10.1016/j.jsat.2017.05.004

56. Pettinati HM, Silverman BL, Battisti JJ, Forman R, Schweizer E, Gastfriend DR. Efficacy of extended-release naltrexone in patients with relatively higher severity of alcohol dependence. Alcohol Clin Exp Res. 2011;35(10):1804-1811. doi:10.1111/j.1530-0277.20 11.01524.x

57. Edelman EJ, Moore BA, Holt SR, et al. Efficacy of extended-release naltrexone on HIV-related and drinking outcomes among HIV-positive patients: a Randomized-Controlled Trial. AIDS Behav. 2019;23(1):211-221. doi:10.1007/s10461-018-2241-Z

58. Springer SA, Altice FL, Herme M, Di Paola A. Design and methods of a double blind randomized placebo-controlled trial of extended-release naltrexone for alcohol dependent and hazardous drinking prisoners with HIV who are transitioning to the community [published correction appears in Contemp Clin Trials. 2017 Jun;57:98]. Contemp Clin Trials. 2014;37(2):209-218. doi:10.1016/ j.cct.2013.12.006

59. Stout RL, Braciszewski JM, Subbaraman MS, et al. What happens when people discontinue taking medications? Lessons from COMBINE. Addictions. 2014;109(12):2044-2052. doi:10.1111/ add. 12700

60. Bigelow GE, Preston KL, Schmittner J, Dong Q, Gastfriend DR. Opioid challenge evaluation of blockade by extended-release naltrexone in opioid-abusing adults: dose-effects and time-course. Drug Alcohol Depend. 2012;123(1-3):57-65. doi:10.1016/j.drugalcdep.2011.10.018 
61. Krupitsky E, Nunes EV, Ling W, Gastfriend DR, Memisoglu A, Silverman BL. Injectable extended-release naltrexone (XR-NTX) for opioid dependence: long-term safety and effectiveness. Addictions. 2013;108(9):1628-1637. doi:10.1111/add.12208

62. Hermes G, Hyman SM, Fogelman N, Kosten TR, Sinha R. Lofexidine in combination with oral naltrexone for opioid use disorder relapse prevention: a pilot randomized, double-blind, Placebo-Controlled Study. Am J Addict. 2019;28:480-488. doi:10.1111/ajad.12942

63. Busch AC, Denduluri M, Glass J, et al. Predischarge injectable versus oral naltrexone to improve postdischarge treatment engagement among hospitalized veterans with alcohol use disorder: a Randomized Pilot Proof-of-Concept Study. Alcohol Clin Exp Res. 2017;41(7):1352-1360. doi:10.1111/acer.13410

64. Friedmann P, Wilson D, Hoskinson R, Poshkus M, Clarke J. Initiation of extended release naltrexone (XR-NTX) for opioid use disorder prior to release from prison. $J$ Subst Abuse Treat. 2018;85:45-48. doi:10.1016/j.jsat.2017.04.010
65. Sullivan MA, Bisaga A, Glass A, et al. Opioid use and dropout in patients receiving oral naltrexone with or without single administration of injection naltrexone. Drug Alcohol Depend. 2015;147:122-129. doi:10.1016/j.drugalcdep.2014.11.028

66. Brantley P, Holtyn A, deFulio A, et al. Effects of incentives for naltrexone adherence on opiate abstinence in heroin-dependent adults. Addiction. 2017;112(5):830-837. doi:10.1111/add.13724

67. Jarvis BP, Holtyn AF, DeFulio A, Dunn KE, Everly JJ, Leoutsakos JS, Umbricht A, Fingerhood M, Bigelow GE, Silverman K. Effects of incentives for naltrexone adherence on opiate abstinence in heroindependent adults. Addiction. 2017;112(5):830-837

\section{Publish your work in this journal}

Patient Preference and Adherence is an international, peer-reviewed, open access journal that focusing on the growing importance of patient preference and adherence throughout the therapeutic continuum. Patient satisfaction, acceptability, quality of life, compliance, persistence and their role in developing new therapeutic modalities and compounds to optimize clinical outcomes for existing disease states are major areas of interest for the journal. This journal has been accepted for indexing on PubMed Central. The manuscript management system is completely online and includes a very quick and fair peer-review system, which is all easy to use. Visit http:// www.dovepress.com/testimonials.php to read real quotes from published authors. 